\title{
Introduction of More Editorial Board Members and Google Maps and Google Earth: the Physician's Cheap Geographic Information System (GIS)
}

In this issue we feature 2 more members of the Fournal of the American Board of Family Medicine's editorial board: Drs. M. Norman Oliver and Adam O. Goldstein.

\section{Norman Oliver, MD, MA}

Dr. Oliver is a guest Editor of this current issue of the $7 A B F M$, which features original research using a geographical information system (GIS) methodology. Dr. Oliver is an Associate Professor in the Department of Family Medicine at the University of Virginia, where his research focuses on investigating social determinants of health, particularly their effect on racial and ethnic health inequities. Dr. Oliver uses GIS technology and spatial epidemiologic analyses to evaluate the role of such factors as poverty and education on cancer health disparities. Currently, Dr. Oliver is conducting a study to assess the effect of unconscious racial stereotypes and biases on physicians' delivery of clinical services.

Dr. Oliver received his medical degree and his MA in medical anthropology from Case Western Reserve University in 1994 and 1992, respectively. He completed his residency in family medicine at University Hospitals of Cleveland in 1996. After residency, Dr. Oliver worked for 2 years as a family physician in a rural Eskimo fishing village in Alaska. He then went to the University of Virginia (UVa) School of Medicine, where he helped found and currently serves as the director of the UVa Center on Health Disparities. Dr. Oliver also directs the Generalist Scholars Program at the UVa School of Medicine and supervises MPH students who have chosen the Health Disparities concentration within that program.

\section{Adam 0. Goldstein, MD, MPH}

Dr. Adam O. Goldstein is a leading US family medicine expert in primary care and a Professor of Family

Conflict of interest: The authors are editors and staff of the 7ABFM.

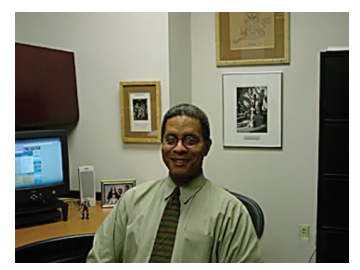

M. Norman Oliver, MD, MA

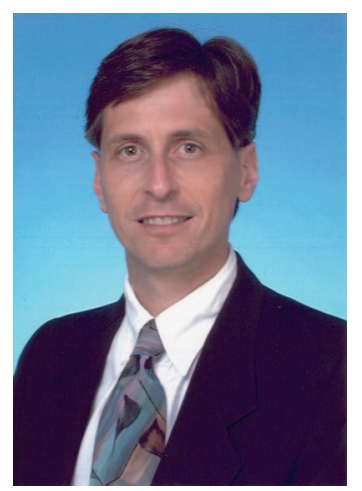

Adam 0. Goldstein, MD, MPH

Medicine at the University of North Carolina School of Medicine. Dr. Goldstein has a 20-year history in clinical practice, teaching, and research, and he has published more than 150 articles, essays, book chapters, and books. Dr. Goldstein is the cohost of Here's To Your Health, a weekly, 1-hour radio show for patients and citizens across North Carolina. He has received local, state, and national recognition for his record of community service. Dr. Goldstein is married to Beth Goldstein, a dermatologist in private practice in Chapel Hill, and he has 3 children: Jared, Michael, and Elianna.

\section{Special GIS Theme Issue}

In this issue, the $7 A B F M$ features several articles using a GIS methodology that encompass the interests of health planners, health policy makers, and health care providers. Many thanks to our guest Editor, Dr. Norm Oliver, for his work reviewing all submissions. We also include studies relevant to 
those concerned with health manpower and to undergraduate and graduate medical educators, as well as board certification.

\section{Google Maps and Google Earth: the Physician's Cheap GIS}

Google Maps and Google Earth are a great advantage to me (MAB) as an urban physician trying to understand my patients in place and context. After reading these GIS-related articles as they were being submitted, I thought about how much I missed not knowing where my patients lived or what their homes were like, which I used to understand when I lived in a smaller community. Philadelphia is a large urban area and my patients come from inside and outside the city. I know much of West Philadelphia (near our offices) and some of Central and South Philadelphia, but our patients also come from many other locales. So I turned to Google Maps, supplemented on occasion by Google Earth. I can always find that street whose name I don't know. I can often see the house or apartment building and I can look up and down the street. Are there broken windows or bars on the street? Is there street lighting or sidewalks? Using Google Earth I can quickly determine whether there are trees or parks nearby. Sometimes nearby restaurants and drug stores are also marked and identified.
The 96-year-old patient who drives a couple of blocks to get to the office? Try more than a few blocks, which scared me. I decided to check more on his ability to drive and alternate forms of transportation. The patient's location that looked just like a field and trees with no house visible? This led to a conversation about how difficult running their small farm was for them: they were being foreclosed and were out of work; there were tears and, eventually, a plan and some relief. The woman who can't get up her front steps and has fallen down them? There are no front steps on any home on her street, which will lead to a conversation next time I see her. The community garden near a patient's home? Maybe she could garden also. Or the man with the business with a vague name, who comes to the office poorly dressed but who apparently lives in a large house in a gated neighborhood? Maybe I don't need to worry so much about the fact that he and his family are uninsured. The woman living alone whose house was surrounded by razed or dilapidated homes and some small manufacturing buildings? Yes, she was lonely and scared as all her neighbors kept moving away. Ah, Google Maps ... one more key to context.

Marjorie A. Bowman, MD, MPA Phillip Lupo, MLIS Anne Victoria Neale, PhD, MPH 